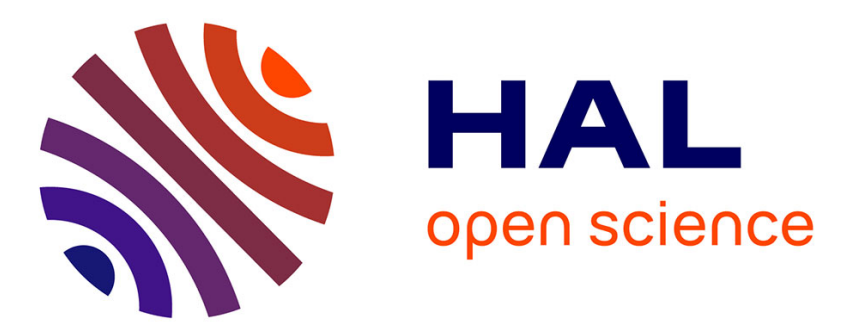

\title{
Dimerization of G protein-coupled receptors: New avenues for somatostatin receptor signalling, control and functioning
}

Mario Durán-Prado, María M. Malagón, F. Gracia-Navarro, Justo P. Castaño

\section{- To cite this version:}

Mario Durán-Prado, María M. Malagón, F. Gracia-Navarro, Justo P. Castaño. Dimerization of G protein-coupled receptors: New avenues for somatostatin receptor signalling, control and functioning. Molecular and Cellular Endocrinology, 2008, 286 (1-2), pp.63. 10.1016/j.mce.2007.12.006 . hal00531972

\section{HAL Id: hal-00531972 \\ https://hal.science/hal-00531972}

Submitted on 4 Nov 2010

HAL is a multi-disciplinary open access archive for the deposit and dissemination of scientific research documents, whether they are published or not. The documents may come from teaching and research institutions in France or abroad, or from public or private research centers.
L'archive ouverte pluridisciplinaire HAL, est destinée au dépôt et à la diffusion de documents scientifiques de niveau recherche, publiés ou non, émanant des établissements d'enseignement et de recherche français ou étrangers, des laboratoires publics ou privés. 


\section{Accepted Manuscript}

Title: Dimerization of G protein-coupled receptors: New avenues for somatostatin receptor signalling, control and functioning

Authors: Mario Durán-Prado, María M. Malagón, F. Gracia-Navarro, Justo P. Castaño

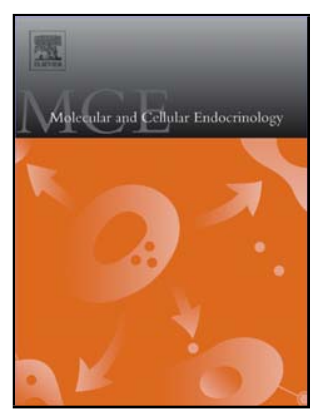

PII: S0303-7207(07)00456-X

DOI: doi:10.1016/j.mce.2007.12.006

Reference: MCE 6770

To appear in: $\quad$ Molecular and Cellular Endocrinology

Received date: $\quad 10-12-2007$

Accepted date: $\quad 11-12-2007$

Please cite this article as: Durán-Prado, M., Malagón, M.M., Gracia-Navarro, F., Castaño, J.P., Dimerization of G protein-coupled receptors: New avenues for somatostatin receptor signalling, control and functioning, Molecular and Cellular Endocrinology (2007), doi:10.1016/j.mce.2007.12.006

This is a PDF file of an unedited manuscript that has been accepted for publication. As a service to our customers we are providing this early version of the manuscript. The manuscript will undergo copyediting, typesetting, and review of the resulting proof before it is published in its final form. Please note that during the production process errors may be discovered which could affect the content, and all legal disclaimers that apply to the journal pertain. 


\section{Dimerization of G protein-coupled receptors: New avenues for somatostatin receptor signalling, control and functioning}

Mario Durán-Prado, María M. Malagón, F. Gracia-Navarro, and Justo P. Castaño

Department of Cell Biology, Physiology and Immunology, University of Cordoba, and CIBER Fisiopatología de la Obesidad y Nutrición CB06/03, Instituto de Salud Carlos III, Cordoba, Spain

Short title: dimerization of somatostatin receptors

Keywords: sst, dimerization, dopamine receptor, fluorescence resonance energy transfer, G protein coupled receptor, heterodimer, homodimer, immunoprecipitation, opioid receptor, somatostatin receptor

Correspondence should be addressed to Dr. Justo P. Castaño: Department of Cell Biology, Physiology and Immunology, Campus de Rabanales, Edificio Severo Ochoa, Planta 3. University of Córdoba, E-14014 Córdoba, Spain. Phone: + 34957218594. Fax: +34 9572186 34. E-mail: justo@uco.es 


\section{Abstract}

Somatostatin acts through binding and activation of five G protein coupled receptors (GPCRs) termed somatostatin receptors or ssts (sst1-sst5). These receptors, as many other GPCRs are not just monomers but display a differential tendency to homodimerize, which varies depending on the sst subtype. Moreover, there is evidence that pairs of distinct receptors such as ssst2-sst3 and sst1-sst5 crosstalk by establishing a physical interaction, which results in altered pharmacological or/and functional properties. In addition, ssts can also heterodimerize with other families of GPCRs, as opioid and dopamine receptors, originating heterodimers which properties are different to those of their separated receptors. The present review summarizes the current knowledge on ssts homodimerization, heterodimerization, and interaction with other GPCRs, as well as how interactions affect different aspects of the normal functioning of these receptors. 


\section{INTRODUCTION}

\section{Receptor dimer as the basic signalling structure}

G protein coupled receptors comprises a large family of membrane proteins characterized by their seven-transmembrane structure. Originally thought to act always as monomers, it is now widely accepted that GPCRs interact to form dimers and supramolecular entities of higher order of complexity (multimers), although the precise contribution of such interactions to receptor function remains somewhat elusive (Bai, 2004; Terrillon and Bouvier, 2004; Bulenger et al., 2005; Pfleger and Eidne, 2005; Prinster et al., 2005; Milligan, 2007). The study of GPCR dimerization received special attention in 1998, when researchers from different groups, while studying GABA $\beta$ receptor, realized that the functional receptor was in fact assembled from two different genetic products and was not a monomer as initially believed (Marshall et al., 1999; Mohler and Fritschy, 1999). More recently, development of atomic force microscopy techniques enabled visualization of rhodopsin molecules in native membranes, and thereby provided unequivocal evidence that receptor dimers and multimers exist (Fotiadis et al., 2003; Liang et al., 2003; Fotiadis et al., 2006). Moreover, an increasing number of studies point at the receptor dimer as the basic signalling structure (Bai, 2004; Terrillon and Bouvier, 2004; Bulenger et al., 2005; Pfleger and Eidne, 2005; Prinster et al., 2005; Milligan, 2007). In fact, this basic signalling structure composed of a dimer of GPCRs and the trimeric $\mathrm{G}$ protein was proposed few years ago from data obtained from the solving of GPCR crystals, which revealed that the size of the cytosolic interface of a monomeric GPCR is much smaller than that required to contact simultaneously with the $\alpha, \beta$ and $y$ subunits of the trimer of $\mathrm{G}$ proteins, whereas it fits that of the dimeric receptor (Hamm, 2001; Baneres and Parello, 2003).

Dimerization of GPCRs has been shown to occur constitutively in the endoplasmic reticulum early after receptor synthesis, and seems to be a prerequisite for their correct targeting and specific subcellular localization (Bulenger et al., 2005). Although the precise 
mechanism of assembly of these monomers to form dimers is relatively unknown, it has been proposed to involve molecular chaperones like 14-3-3, HSP70 or receptor activity modifying proteins (RAMPs) (Bulenger et al., 2005). Actually, GPCRs are not the only molecules that dimerize after their synthesis, since other proteins, such as insulin receptors, TGF receptors and $\mathrm{K}^{+}$channels also dimerize, thereby suggesting that a common and conserved control mechanism may operate at a posttranslational level, even for different families of unrelated proteins (Bulenger et al., 2005).

Interestingly, although constitutive dimerization appears to be essential for GPCR functioning, not all GPCRs exhibit the same degree of dimerization, which is variable and depends on the type of receptor (Milligan, 2004; Bulenger et al., 2005; Pfleger and Eidne, 2005). For example, when $\beta$-adrenergic receptors are transfected in the HEK-293 AD cell line at a "physiological level", around $85 \%$ are forming dimers (Mercier et al., 2002). In contrast, a variable percentage of dimers ranging from $26-44 \%$ was found for neuropeptide $Y$ receptors (Dinger et al., 2003). Moreover, GPCRs dimerization is also regulated by ligand binding, yet, again, not all receptors operate similarly (Milligan, 2004; Pfleger and Eidne, 2005). Actually, behaviour of receptors belonging to the same family can be opposite, as reported for somatostatin receptors sst2 and sst5, whose dimerization decreases or increases, respectively, after ligand binding (Grant et al., 2004; Grant et al., 2004). Furthermore, whereas binding of adenosine $\mathrm{A} 1$ and purine $\mathrm{P} 2 \mathrm{Y} 1$ increases receptor oligomerization from a dimeric basal state (Yoshioka et al., 2002), binding of chemokines to CXCR4 promotes oligomerization from a monomeric basal state (Vila-Coro et al., 1999). On the other hand, it has also been reported that ligand binding induces the converse effect, so that binding of NPY, TRH and cholecystokinin to their respective receptors induces the dissociation of the assembled dimers/oligomers (Cheng and Miller, 2001; Latif et al., 2001; Berglund et al., 2003) which might be related to further endocytic processes (Gregan et al., 2004). Finally, dimeric state of some receptors remains constitutive and insensitive to ligand binding, as reported for the MTR1 receptor or the murine sst2 and sst3 (Pfeiffer et al., 2001; Ayoub et al., 2002). 


\section{GPCR HETERODIMERIZATION: A source of functional diversification}

If homodimerization seems essential for the correct functionality of GPCRs, heterodimerization results in the diversification of their functioning, in terms of ligand binding, signalling, control of endocytic processes, etc., (Milligan, 2007). In some instances, heterodimerization becomes critical for the normal functionality of the GPCR, as is the case of the GABA $\beta$ receptor (Marshall et al., 1999; Mohler and Fritschy, 1999). An extreme example is the family of opioid receptors, composed of three members, $\kappa, \delta$ and $\mu$, whose heterodimerization properties confer the family an extremely complex pharmacology, difficult to understand as a mere result of the three isolated genetic products, $k, \delta$ and $\mu$ receptors (Jordan and Devi, 1999; Jordan et al., 2000; Levac et al., 2002; Snyder and Pasternak, 2003). Thus, functional capabilities of GPCRs are diversified by interaction between receptors of the same or different families, which is rather common. Indeed, different receptors coexpressed in the same cell present certain promiscuity to heterodimerize (Jordan et al., 2001; McVey et al., 2001; Pfeiffer et al., 2002; Salim et al., 2002).

Heterodimerization between two GPCRs belonging to the same or different families can affect diverse aspects of receptor functioning. For instance, it can modify ligand binding affinity as described for the adrenergic A1 and purinergic P2Y1 receptors. Specifically, interaction between this couple of receptors reduces the affinity for the A1 receptor specific ligands, while increases the affinity for the P2Y1 receptor selective ligands (Yoshioka et al., 2001). Interaction between two receptors can also block the normal function of a receptor. For example, interaction of a truncated variant of the receptor for chemokines CCR2 with CCR5 or CXCR4 receptors result in a blockade of HIV infection due to the inability of the virus to bind these latter receptors (Mellado et al., 1999). Similarly, interaction between sst2 and sst3 receptors results in the inactivation of this latter sst (Pfeiffer et al., 2001). Additionally, heterodimerization can alter the endocytic properties of GPCRs, as it is the case for angiotensin AT1 and bradykinin B2 receptors, wherein the heteroreceptor is endocyted by a 
dynamin dependent pathway, while the homodimers internalize following pathways independent of clathrin and dynamin (AbdAlla et al., 2000).

Heterodimerization can also influence signal transduction though a change in $G$ protein coupling. For instance, coexpression of $\mu$ and $\delta$ opioid receptors results in a heterodimer insensitive to pertusis toxin treatment, whereas their corresponding homodimers are sensitive to this toxin (George et al., 2000). Similarly, interaction between A1 and purinergic P2Y1 receptors results in a preferential signalling via $G_{i}$ protein rather than the normal $G_{q}$ signalling of the homodimers (Yoshioka et al., 2001). Likewise, the CCR2/CCR5 heterodimer is preferentially coupled to $G_{q / 11}$ proteins, which leads to a delay in phosphatidyl inositol 3-kinase activation and in an induction of cell adhesion instead of chemotaxis, and thereby entail important functional consequences (Mellado et al., 2001). Thus, when taken together, the results reported hitherto clearly demonstrate that homo- and heterodimerization processes comprise a set of powerful mechanisms to modulate GPCR functioning, which provides an additional step of complexity and versatility in this large family of receptors. In this scenario, it seems of interest to look at the studies that have examined these processes in the case of the somatostatin receptors.

\section{DIMERIZATION OF SOMATOSTATIN RECEPTORS}

\section{Homodimerization of somatostatin receptors}

The family of somatostatin receptors (ssts) comprises five different class A peptide receptors, sst1-sst5, encoded by five genes, wherein one of them, sst2A, has been shown to have a splice variant, sst2B, bearing a distinct carboxy terminal domain (Olias et al., 2004). The main structural and functional features of ssts, including their pharmacology, signalling, endocytosis and recycling, have been extensively characterized using both primary cell cultures and, specially, cell lines stably transfected with different receptors from diverse species, and this information has been carefully reviewed (Moller et al., 2003; Jacobs and Schulz, 2007; Schonbrunn, 2007; Siehler et al., 2007, in this issue). On the other hand, two 
important processes such as sst homo- and heterodimerization still remain relatively unexplored, in spite of the fact that coexpression of two or more sst in a given cell type appears to be the rule rather than the exception (Moller et al., 2003; Olias et al., 2004). In line with this, work by different groups has evidenced that, as for other GPCRs, some ssts are capable to form homo- and heterodimers, yet not all the isoforms possess the same ability to interact.

Amongst ssts, sst2 is the most abundantly expressed and widely distributed receptor subtype (Moller et al., 2003; Olias et al., 2004). This receptor has been also the subject of most studies carried out on sst homodimerization, yet information reported regarding sst2 from different species refers to data obtained using disparate biochemical and biophysical approaches, thereby rendering comparisons somewhat difficult (Pfeiffer et al., 2001; Grant et al., 2004; Duran-Prado et al., 2007). To study dimerization of human sst2 a double approach consisting of immunoprecipitation assays combined with fluorescence resonance energy transfer (FRET) measurements was carried out (Grant et al., 2004). Use of these techniques revealed that the human receptor, transfected in either CHO-K1 or HEK-293 T cells, forms constitutive homodimers, showing a FRET efficiency close to $12 \%$, which was consistent, at least in part, with immunoprecipitation assays. Moreover, its dimeric state was irreversibly diminished by treatment with increasing concentrations of somatostatin and independent of the expression level of the receptor (Grant et al., 2004). Similarly, the rat sst2 homologue transfected in HEK-293 T cells forms dimers as demonstrated by immunoprecipitation assays (Pfeiffer et al., 2001). However, treatment with somatostatin did not appear to alter its dimeric state, albeit the time-window tested may have precluded the observation of changes in dimerization of the receptor. More recently, studies on porcine sst2 transfected in CHO-K1 showed, by FRET, that as for its human and murine counterparts, around $50 \%$ of porcine sst2 form dimers constitutively, an observation that was also reproduced in HEK-293 AD cells (Duran-Prado et al., 2007). Moreover, monitoring of FRET in living cells demonstrated that treatment with somatostatin promotes a rapid dissociation of the dimers, similar to that found 
for its human counterpart, but the original dimeric state of porcine sst2 is subsequently recovered, just few seconds after dissociation, a phenomenon that is in clear contrast to that observed for its human homologue (Duran-Prado et al., 2007). Although these apparent discrepancies could be due to the different methodological approaches used in each study, it is also plausible that the precise spatial and temporal dynamics of ligand-induced receptor dimerization, dissociation and internalization of sst2 are subject to interspecies-dependent variations.

Analysis of the dimerization of human sst5 in the same cell lines used for sst2 has shown that each receptor displays a different behaviour (Grant et al., 2004). More specifically, while sst2 forms constitutive dimers, sst5 does not seems to dimerize after its synthesis. On the other hand, treatment with somatostatin induces human sst5 dimerization, opposite to that found for human sst2, which dissociates after ligand binding (Grant et al., 2004). Nevertheless, there is evidence that homodimerization of the receptor could be influenced by its expression level. In particular, sst5 homodimerizes at high expression levels but does not seem to aggregate at lower levels, which are considered physiological (Rocheville et al., 2000; Patel et al., 2002).

Dimerization of rat sst3 has been studied by immunoprecipitation and western blot (Pfeiffer et al., 2001). This showed that, similar to rat sst2, the receptor transfected in the HEK-293 T cell line forms constitutive dimers, which does not appear to be altered by ligand binding (Pfeiffer et al., 2001). However, since the methodology used in these studies on rat receptors can not detect rapid temporal dissociation-association events, as those described for the porcine sst2 (Duran-Prado et al., 2007) it can not be excluded that the short-term, ligand-induced dynamics of both murine sst2 and sst3 are similar to those of porcine sst2.

Available information, obtained through different technical approaches, indicates that human sst1 never forms homodimers (Patel et al., 2002). Specifically, sst1 dimerization was first evaluated by photobleaching FRET in transfected $\mathrm{CHO}-\mathrm{K} 1$ cells, using different 
somatostatin derivatives labelled with FITC and rhodamine, an indirect approach that revealed that this receptor, at the expression level assayed, remains monomeric (Patel et al., 2002). These results were further corroborated by immunoprecipitation and western blot using the same cell line stably transfected with the receptor (Grant et al., 2004). Thus, sst1 appears to be synthesized as a monomer, an this state would not be altered by ligand binding (Patel et al., 2002; Grant et al., 2004). Intriguingly, the monomeric receptor is functional, indicating that dimerization or oligomerization does not seem to be a requisite for the correct functioning of this specific human sst subtype.

\section{Heterodimerization of somatostatin receptors}

The process of heterodimerization by which individual sst interact to form hetero-dimeric or heteromultimeric complexes could be of particular importance in the sst family, since, as mentioned above, it is quite frequent that two or more sst receptor subtypes are coexpressed in a given cell type. Interestingly, interactions among sst, rather than random seem to be highly selective, as not all the potential combinations occur. However, not all the possibilities of sst heterodimers have been explored hitherto, since the interactions characterized so far are between murine sst2 and sst3 (Pfeiffer et al., 2001) and human sst1 and sst5 couples (Rocheville et al., 2000). Nevertheless, results reported to date clearly indicate that heterodimerization among these sst subtypes causes distinct effects on sst functioning. Thus, heterodimerization between rat sst2 and sst3 receptors results in the inactivation of the sst3, while the function of the sst2 remains unaltered (Pfeiffer et al., 2001). Furthermore, this heterodimer is unable to bind selective ligands for the sst3 subtype (Pfeiffer et al., 2001). In addition, the endocytic process of these receptors is modified after heterodimerization: while sst2 endocytosis is not affected, sst3 internalization is drastically impaired. In line with this, the sst2-sst3 heterodimer also shows certain resistance to desensitisation, as it does so at a smaller rate than the sst2 or sst3 homodimers (Pfeiffer et al., 2001). 
Interaction between human sst1 and sst5 also affects some functional properties of the isolated monomers/homodimers (Rocheville et al., 2000). Accordingly, their cotransfection in $\mathrm{CHO}-\mathrm{K} 1$ cells results in an increased ligand affinity for somatostatin. Moreover, the heterodimer is also unique regarding to the endocytic process, because it retains a smaller tendency to internalize than the sst5 homodimer in response to a specific sst5 ligand, whereas it internalizes better than the sst1 monomer in response to a sst1 specific ligand (Rocheville et al., 2000). In addition, interaction between sst1 and sst5 results in the upregulation of the latter at the plasma membrane in response to sst5 specific ligands, which does not occur in sst5 monotransfected cells (Rocheville et al., 2000). Moreover, though not proven, this interaction is thought to alter signalling in terms of cAMP modulation (Rocheville et al., 2000).

\section{Ssts heterodimerization with opioid and dopamine receptors}

Functioning of ssts can also be altered as a consequence of these receptors physically interacting with other families of GPCRs as opioid (Pfeiffer et al., 2002) and dopamine receptors (Rocheville et al., 2000; Baragli et al., 2007), a phenomenon that originates new receptors with altered pharmacological and/or functional properties.

In particular, murine sst2 has been shown to heterodimerize with the $\mu$-opioid receptor, MOR1 in cotransfected HEK-293T cells (Pfeiffer et al., 2002). Interestingly, their physical interaction neither alters their pharmacology nor their signalling properties. However, while treatment with a selective sst2 ligand, L-779,976, promotes phosphorylation, desensitisation and endocytosis of both, sst2 and MOR1 receptors, treatment with the MOR1 specific ligand DAMGO induces phosphorylation and desensitisation of both receptors, but it does not lead to sst2 internalization (Pfeiffer et al., 2002).

Interaction between ssts and dopamine receptors provided the first evidence that sst could undergo heterodimerization with non-sst receptors. Human sst5 and dopamine 2 receptor (D2R) interaction was initially suspected because both receptors colocalized in some cortical neurons (Rocheville et al., 2000). Their interaction was demonstrated by 
complementation assays and photobleaching FRET in CHO-K1 cells cotransfected with both receptors. Interestingly, at basal state, in the absence of ligands, these receptors do not interact: D2R forms dimers and sst5 remains monomeric. However treatment with ligands for any of the receptors dramatically induces heterodimerization (Rocheville et al., 2000). The sst5-D2R heterodimer is pharmacological and functionally different from the sst5 or D2R. Thus, binding of quinpirole, a D2R agonist, increases binding affinity of somatostatin by $3000 \%$, whereas a D2R antagonist, sulpiride, decreases binding affinity for the peptide in an $80 \%$. This enhanced or decreased affinity for somatostatin is translated in an amplified or diminished ability to inhibit forskolin-stimulated cAMP levels after treatment with the peptide (Rocheville et al., 2000).

Very recently, interaction between the D2R and the human sst2 has been also reported (Baragli et al., 2007). As for the sst5-D2R heterodimer, sst2 and D2R do not heterodimerize under basal conditions, but their interaction is induced by ligand binding (Baragli et al., 2007). Their interaction results in a heterodimer with an increased affinity for dopamine, which is also accompanied by an increased signalling via D2R receptor. Conversely, sst2 pharmacology and signalling are not altered by heterodimerization with the $\mathrm{D} 2 \mathrm{R}$, but its endocytic rate is increased as consequence of this interaction (Baragli et al., 2007).

\section{Concluding remarks}

There is an increasing body of evidence indicating that, as for other GPCRs, ssts do not "live" as isolated, simple monomers in the plasma membrane of the cells, but that they associate with other receptors to form molecular complexes of hierarchically higher magnitude, whose binding, pharmacological and signalling properties can diverge substantially from those of the corresponding single receptors. For each sst subtype, a wide range of potential interactions could be expected, from the more simple homodimer to the highly complex heterodimer with a non-sst receptor. However, we are still far form elucidating whether all those potential interactions do occur in the native cell, and, if so, from assessing 
what is their precise functional relevance. In fact, although available data already indicates that the pattern of dimer formation and its dynamic behaviour after ligand binding is subtype specific and can also be species-dependent, there is still no evidence to support that (and how) these differences can influence some aspects of sst functioning, as seemingly simple as the different subcellular localization of sst1, sst2 and sst5 transfected in $\mathrm{CHO}-\mathrm{K} 1$ cells, or their dissimilar ability to desensitize after ligand binding.

Most importantly, sst heterodimerization, specially with other GPCRs can represent a versatile mechanism whereby the cell generates a new "receptor" with specific properties distinct from those of their monomers/homodimers, which provides additional functional resources to the cell. For example, it is conceivable that this type of homo/heterodimerizations are involved in the differential actions of somatostatin and a closely related peptide cortistatin in processes where this two structurally similar peptides exert disparate effects, like slow-wave sleep induction and locomotor activity reduction or in the specific role of cortistatin as a potent immunomodulator (de Lecea and Castano, 2006; Gonzalez-Rey and Delgado, 2007, this issue). In this same context, heterodimers may also represent a new drug target with potential clinical applications in the future. Thus, the precise identification and functional characterization of sst homo- and heterodimers constitutes a promising goal that could open new avenues to understand the physiology of somatostatin receptors and their natural and synthetic ligands in health and disease.

\section{Acknowledgements}

This work was supported by grants CVI-139 and CTS-0175 (Plan Andaluz de Investigación, Junta de Andalucía, Spain), BFU2004-03883, BFU2007-60180/BFI (Ministerio de Educación y Ciencia, Spain/FEDER). 


\section{References}

AbdAlla, S., Lother, H. and Quitterer, U. (2000) AT1-receptor heterodimers show enhanced Gprotsein activation and altered receptor sequestration. Nature 407, 94-8.

Ayoub, M.A., Couturier, C., Lucas-Meunier, E., Angers, S., Fossier, P., Bouvier, M. and Jockers, R. (2002) Monitoring of ligand-independent dimerization and ligand-induced conformational changes of melatonin receptors in living cells by bioluminescence resonance energy transfer. J Biol Chem 277, 21522-8.

Bai, M. (2004) Dimerization of G-protein-coupled receptors: roles in signal transduction. Cell Signal 16, 175-86.

Baneres, J.L. and Parello, J. (2003) Structure-based analysis of GPCR function: evidence for a novel pentameric assembly between the dimeric leukotriene B4 receptor BLT1 and the G-protein. J Mol Biol 329, 815-29.

Baragli, A., Alturaihi, H., Watt, H.L., Abdallah, A. and Kumar, U. (2007) Heterooligomerization of human dopamine receptor 2 and somatostatin receptor 2 Co-immunoprecipitation and fluorescence resonance energy transfer analysis. Cell Signal.

Berglund, M.M., Schober, D.A., Esterman, M.A. and Gehlert, D.R. (2003) Neuropeptide Y Y4 receptor homodimers dissociate upon agonist stimulation. J Pharmacol Exp Ther 307, $1120-6$.

Bulenger, S., Marullo, S. and Bouvier, M. (2005) Emerging role of homo- and heterodimerization in G-protein-coupled receptor biosynthesis and maturation. Trends Pharmacol Sci 26, 131-7.

Cheng, Z.J. and Miller, L.J. (2001) Agonist-dependent dissociation of oligomeric complexes of $G$ protein-coupled cholecystokinin receptors demonstrated in living cells using bioluminescence resonance energy transfer. J Biol Chem 276, 48040-7.

de Lecea, L. and Castano, J.P. (2006) Cortistatin: not just another somatostatin analog. Nat Clin Pract Endocrinol Metab 2, 356-7.

Dinger, M.C., Bader, J.E., Kobor, A.D., Kretzschmar, A.K. and Beck-Sickinger, A.G. (2003) Homodimerization of neuropeptide y receptors investigated by fluorescence resonance energy transfer in living cells. J Biol Chem 278, 10562-71.

Duran-Prado, M., Bucharles, C., Gonzalez, B.J., Vazquez-Martinez, R., Martinez-Fuentes, A.J., Garcia-Navarro, S., Rhodes, S.J., Vaudry, H., Malagon, M.M. and Castano, J.P. (2007) Porcine somatostatin receptor 2 displays typical pharmacological sst2 features but unique dynamics of homodimerization and internalization. Endocrinology 148, 41121. 
Fotiadis, D., Jastrzebska, B., Philippsen, A., Muller, D.J., Palczewski, K. and Engel, A. (2006) Structure of the rhodopsin dimer: a working model for G-protein-coupled receptors. Curr Opin Struct Biol 16, 252-9.

Fotiadis, D., Liang, Y., Filipek, S., Saperstein, D.A., Engel, A. and Palczewski, K. (2003) Atomic-force microscopy: Rhodopsin dimers in native disc membranes. Nature 421, 127-8.

George, S.R., Fan, T., Xie, Z., Tse, R., Tam, V., Varghese, G. and O'Dowd, B.F. (2000) Oligomerization of mu- and delta-opioid receptors. Generation of novel functional properties. J Biol Chem 275, 26128-35.

Gonzalez-Rey, E. and Delgado, M. (2007) Emergence of cortistatin as a new immunomodulatory factor with therapeutic potential in immune disorders. Mol Cell Endocrinol.

Grant, M., Collier, B. and Kumar, U. (2004) Agonist-dependent dissociation of human somatostatin receptor 2 dimers: a role in receptor trafficking. J Biol Chem 279, 3617983.

Grant, M., Patel, R.C. and Kumar, U. (2004) The role of subtype-specific ligand binding and the C-tail domain in dimer formation of human somatostatin receptors. J Biol Chem 279, 38636-43.

Gregan, B., Jurgensen, J., Papsdorf, G., Furkert, J., Schaefer, M., Beyermann, M., Rosenthal, W. and Oksche, A. (2004) Ligand-dependent differences in the internalization of endothelin A and endothelin B receptor heterodimers. J Biol Chem 279, 27679-87.

Hamm, H.E. (2001) How activated receptors couple to G proteins. Proc Natl Acad Sci U S A 98, 4819-21.

Jacobs, S. and Schulz, S. (2007) Intracellular trafficking of somatostatin receptors. Mol Cell Endocrinol.

Jordan, B.A., Cvejic, S. and Devi, L.A. (2000) Opioids and their complicated receptor complexes. Neuropsychopharmacology 23, S5-S18.

Jordan, B.A. and Devi, L.A. (1999) G-protein-coupled receptor heterodimerization modulates receptor function. Nature 399, 697-700.

Jordan, B.A., Trapaidze, N., Gomes, I., Nivarthi, R. and Devi, L.A. (2001) Oligomerization of opioid receptors with beta 2-adrenergic receptors: a role in trafficking and mitogenactivated protein kinase activation. Proc Natl Acad Sci U S A 98, 343-8.

Latif, R., Graves, P. and Davies, T.F. (2001) Oligomerization of the human thyrotropin receptor: fluorescent protein-tagged hTSHR reveals post-translational complexes. J Biol Chem 276, 45217-24. 
Levac, B.A., O'Dowd, B.F. and George, S.R. (2002) Oligomerization of opioid receptors: generation of novel signaling units. Curr Opin Pharmacol 2, 76-81.

Liang, Y., Fotiadis, D., Filipek, S., Saperstein, D.A., Palczewski, K. and Engel, A. (2003) Organization of the $G$ protein-coupled receptors rhodopsin and opsin in native membranes. J Biol Chem 278, 21655-62.

Marshall, F.H., Jones, K.A., Kaupmann, K. and Bettler, B. (1999) GABAB receptors - the first 7TM heterodimers. Trends Pharmacol Sci 20, 396-9.

McVey, M., Ramsay, D., Kellett, E., Rees, S., Wilson, S., Pope, A.J. and Milligan, G. (2001) Monitoring receptor oligomerization using time-resolved fluorescence resonance energy transfer and bioluminescence resonance energy transfer. The human delta opioid receptor displays constitutive oligomerization at the cell surface, which is not regulated by receptor occupancy. J Biol Chem 276, 14092-9.

Mellado, M., Rodriguez-Frade, J.M., Vila-Coro, A.J., de Ana, A.M. and Martinez, A.C. (1999) Chemokine control of HIV-1 infection. Nature 400, 723-4.

Mellado, M., Rodriguez-Frade, J.M., Vila-Coro, A.J., Fernandez, S., Martin de Ana, A., Jones, D.R., Toran, J.L. and Martinez, A.C. (2001) Chemokine receptor homo- or heterodimerization activates distinct signaling pathways. Embo J 20, 2497-507.

Mercier, J.F., Salahpour, A., Angers, S., Breit, A. and Bouvier, M. (2002) Quantitative assessment of beta 1- and beta 2-adrenergic receptor homo- and heterodimerization by bioluminescence resonance energy transfer. J Biol Chem 277, 44925-31.

Milligan, G. (2007) G protein-coupled receptor dimerisation: molecular basis and relevance to function. Biochim Biophys Acta 1768, 825-35.

Milligan, G. (2004) G protein-coupled receptor dimerization: function and ligand pharmacology. Mol Pharmacol 66, 1-7.

Mohler, H. and Fritschy, J.M. (1999) GABAB receptors make it to the top--as dimers. Trends Pharmacol Sci 20, 87-9.

Moller, L.N., Stidsen, C.E., Hartmann, B. and Holst, J.J. (2003) Somatostatin receptors. Biochim Biophys Acta 1616, 1-84.

Olias, G., Viollet, C., Kusserow, H., Epelbaum, J. and Meyerhof, W. (2004) Regulation and function of somatostatin receptors. J Neurochem 89, 1057-91.

Patel, R.C., Kumar, U., Lamb, D.C., Eid, J.S., Rocheville, M., Grant, M., Rani, A., Hazlett, T., Patel, S.C., Gratton, E. and Patel, Y.C. (2002) Ligand binding to somatostatin receptors induces receptor-specific oligomer formation in live cells. Proc Natl Acad Sci U S A 99, 3294-9.

Pfeiffer, M., Koch, T., Schroder, H., Klutzny, M., Kirscht, S., Kreienkamp, H.J., Hollt, V. and Schulz, S. (2001) Homo- and heterodimerization of somatostatin receptor subtypes. 
Inactivation of sst(3) receptor function by heterodimerization with $\operatorname{sst}(2 \mathrm{~A})$. J Biol Chem 276, 14027-36.

Pfeiffer, M., Koch, T., Schroder, H., Laugsch, M., Hollt, V. and Schulz, S. (2002) Heterodimerization of somatostatin and opioid receptors cross-modulates phosphorylation, internalization, and desensitization. J Biol Chem 277, $19762-72$.

Pfleger, K.D. and Eidne, K.A. (2005) Monitoring the formation of dynamic G-protein-coupled receptor-protein complexes in living cells. Biochem J 385, 625-37.

Prinster, S.C., Hague, C. and Hall, R.A. (2005) Heterodimerization of g protein-coupled receptors: specificity and functional significance. Pharmacol Rev 57, 289-98.

Rocheville, M., Lange, D.C., Kumar, U., Patel, S.C., Patel, R.C. and Patel, Y.C. (2000) Receptors for dopamine and somatostatin: formation of hetero-oligomers with enhanced functional activity. Science 288, 154-7.

Rocheville, M., Lange, D.C., Kumar, U., Sasi, R., Patel, R.C. and Patel, Y.C. (2000) Subtypes of the somatostatin receptor assemble as functional homo- and heterodimers. J Biol Chem 275, 7862-9.

Salim, K., Fenton, T., Bacha, J., Urien-Rodriguez, H., Bonnert, T., Skynner, H.A., Watts, E., Kerby, J., Heald, A., Beer, M., McAllister, G. and Guest, P.C. (2002) Oligomerization of G-protein-coupled receptors shown by selective co-immunoprecipitation. J Biol Chem 277, 15482-5.

Schonbrunn, A. (2007) Selective agonism in somatostatin receptor signaling and regulation. Mol Cell Endocrinol.

Siehler, S., Nunn, C., Hannon, J.P., Feuerbach, D. and Hoyer, D. (2007) Pharmacological Profile of Somatostatin and Cortistatin Receptors. Mol Cell Endocrinol In press.

Snyder, S.H. and Pasternak, G.W. (2003) Historical review: Opioid receptors. Trends Pharmacol Sci 24, 198-205.

Terrillon, S. and Bouvier, M. (2004) Roles of G-protein-coupled receptor dimerization. EMBO Rep 5, 30-4.

Vila-Coro, A.J., Rodriguez-Frade, J.M., Martin De Ana, A., Moreno-Ortiz, M.C., Martinez, A.C. and Mellado, M. (1999) The chemokine SDF-1alpha triggers CXCR4 receptor dimerization and activates the JAK/STAT pathway. Faseb J 13, 1699-710.

Yoshioka, K., Saitoh, O. and Nakata, H. (2001) Heteromeric association creates a P2Y-like adenosine receptor. Proc Natl Acad Sci U S A 98, 7617-22.

Yoshioka, K., Saitoh, O. and Nakata, H. (2002) Agonist-promoted heteromeric oligomerization between adenosine $A(1)$ and $P 2 Y(1)$ receptors in living cells. FEBS Lett 523, 147-51. 